https://doi.org/10.29296/25877305-2018-09-15

\section{Возраст пациентов}

\section{и динамика ЭКГ}

\section{при нейролептической}

\section{кардиомиопатии}

В. Волков, кандидат медицинских наук Тверской центр судебных экспертиз

E-mail: patowolf@yandex.ru

Установлено, что решающее влияние на динамику электрокардиографических показателей при развитии нейролептической кардиомиопатии оказывает не возрастной фактор, а побочное кардиотоксическое действие антипсихотических средств, приводящее к развитию кардиальной патологии

Ключевые слова: кардиология, психиатрия, антипсихотические препараты, кардиотоксичность, нейролептическая кардиомиопатия, изменения электрокардиограммы, влияние возраста.

Для цитирования: Волков В. Возраст пациентов и динамика ЭКГ при нейролептической кардиомиопатии // Врач. - 2018; 29 (9): 65-67. https://doi. org/10.29296/25877305-2018-09-15

$\mathrm{B}$ следствие активной терапии при лечении как основной психической, так и сопутствующей соматической патологии значительно увеличилась продолжительность жизни психически больных, в частности страдающих шизофренией [1]. Этот процесс сопровождается существенным удлинением сроков антипсихотической терапии (АПТ), в результате заметно увеличивается время повреждающего кардиотоксического воздействия антипсихотических средств (АП) на сердце, что чревато развитием тяжелой, опасной для жизни ятрогенной патологии - нейролептической кардиомиопатии (НКМП) [3, 4, 10, 14].

Отражением глубоких структурных изменений миокарда в процессе морфогенеза НКМП служат разнообразные патологические сдвиги на электрокардиограмме (ЭКГ) [2, 4].

Параллельно в сердце протекают и естественные онтогенетические инволюционные процессы [5]. Так, особенностями ЭКГ практически здоровых людей пожилого возраста являются правильный синусовый ритм; синусовая брадикардия; отклонение электрической оси сердца (ЭОС) влево; расширение, уплощение и деформация зубца $P$; удлинение интервалов $P Q$ и $Q T$, уширение, расщепление и снижение вольтажа комплекса $Q R S$; уменьшение амплитуды зубца $T$ во всех отведениях; экстрасистолия, блокады ножек пучка Гиса $[8,12,13]$.
В связи с изложенным закономерно возникает вопрос: как взаимодействуют между собой такие факторы, как АПТ и возраст, и каково значение прямого действия возрастного фактора в формировании изменений, регистрируемых на ЭКГ при развитии НКМП?

В специальной литературе каких-либо сведений по этой проблеме нами не обнаружено. Между тем внесение ясности в этот вопрос имеет немаловажное практическое значение, поскольку АП обычно назначают психиатры, которые, как правило, мало осведомлены о кардиологических нюансах [15]. Кроме того, изучение ЭКГ-эквивалентов побочного кардиотоксического эффекта АП крайне важно для клинической практики, поскольку именно появление на ЭКГ аномальных знаков является одним из относительно ранних признаков развивающейся НКМП [6].

Нами ретроспективно изучены истории болезни 43 больных шизофренией (27 мужчин, 16 женщин), умерших в возрасте моложе 40 лет и старше 60 лет, разделенных на 4 группы: 1-ю и 2-ю группу составили соответственно 8 молодых и 12 пожилых пациентов, получавших АП, но без сердечной патологии, умерших от некардиальных причин; в 3-ю и 4-ю группу вошли соответственно 6 молодых и 17 пожилых больных, страдавших НКМП. Изучено 133 ЭКГ больных 1-4-й групп (соответственно 23; 34; 21 и 55 ЭКГ). В каждой их групп ранжировалось 8 электрофизиологических феноменов (ЭКГ-знаков), в том числе корригированный интервал QT $(Q T c)$ по Н. Bazett [7].

Математический анализ полученных количественных данных включал вычисление такого индекса, как размер эффекта по J. Cohen $[9,11]$, который в количественном выражении определяет силу воздействия изучаемого фактора на тот или иной объект исследования [9]. Для статистических расчетов использована компьютерная программа Statistica 6.0 с уровнем значимости различий $\geq 95 \%(\mathrm{p} \leq 0,05)$.

При сравнении показателей ЭКГ в 1-й и 2-й группах (табл. 1) выявлены существенные и статистически значимые онтогенетические изменения 6 из 8 параметров ЭКГ. Так, с возрастом снижается частота тахикардии, являющейся побочным эффектом большинства АП [3]. По-видимому, это связано с заметным учащением нарушений проводимости, в том числе пролонгации интервала $Q T c$, что, как известно, обусловлено прямым воздействием АП на ионные каналы кардиомиоцитов [3].

Определенным частотным сдвигам, свидетельствующим о возрастных изменениях миокарда преимущественно левого желудочка (ЛЖ), подвержены и такие ЭКГ-знаки, как диффузные мышечные изменения, снижение электрической активности миокарда и отклонение ЭОС влево.

Расчет d'C в сравниваемых 1-й и 2-й группах (табл. 2) показывает, что на такой показатель, как отклонение ЭОС влево, возраст влияет лишь в средней 
Частота ЭКГ-знаков в исследованных группах; \%

\begin{tabular}{|c|c|c|c|c|c|c|c|c|}
\hline Группа & $\begin{array}{c}\text { Нарушение } \\
\text { ритма }\end{array}$ & $\begin{array}{c}\text { Удлинение } \\
\text { интервала } \\
\text { QTс }\end{array}$ & $\begin{array}{c}\text { Нарушение } \\
\text { проводимости }\end{array}$ & $\begin{array}{c}\text { Диффузные } \\
\text { мышечные } \\
\text { изменения }\end{array}$ & $\begin{array}{c}\text { Перегрузка } \\
\text { правых } \\
\text { отделов }\end{array}$ & $\begin{array}{c}\text { Гипертрофия } \\
\text { ЛЖ }\end{array}$ & $\begin{array}{c}\text { Снижение } \\
\text { электрической } \\
\text { активности миокарда }\end{array}$ & $\begin{array}{c}\text { Отклонение } \\
\text { ЭОС влево }\end{array}$ \\
\hline 1-я & $83,9 \pm 15,1^{2,4}$ & $8,6 \pm 4,2^{2-4}$ & $7,4 \pm 4,9^{2-4}$ & $15,3 \pm 4,4^{2-4}$ & $8,7 \pm 4,7^{3,4}$ & $2,4 \pm 1,4^{3,4}$ & $1,4 \pm 1,0^{2-4}$ & $3,8 \pm 2,5^{2-4}$ \\
\hline 2-я & $56,4 \pm 10,8^{1}$ & $21,2 \pm 7,1^{1,4}$ & $22,4 \pm 8,3^{1,4}$ & $25,4 \pm 8,8^{1,4}$ & $12,0 \pm 5,7^{3,4}$ & $9,6 \pm 7,7^{4}$ & $7,9 \pm 3,3^{1,4}$ & $15,7 \pm 4,9^{1,4}$ \\
\hline 3-я & $67,7 \pm 15,7$ & $21,9 \pm 11,2^{1,4}$ & $33,7 \pm 10,8^{1}$ & $34,7 \pm 4,8^{1}$ & $24,9 \pm 9,2^{1,2}$ & $13,5 \pm 6,1^{1}$ & $11,6 \pm 6,1^{1}$ & $19,2 \pm 5,9^{1}$ \\
\hline 4-я & $64,1 \pm 8,6^{1}$ & $47,4 \pm 6,8^{1-3}$ & $35,4 \pm 7,3^{1,2}$ & $38,8 \pm 5,7^{1,2}$ & $27,5 \pm 6,4^{1,2}$ & $21,2 \pm 5,8^{1,2}$ & $21,3 \pm 7,7^{1,2}$ & $28,2 \pm 7,3^{1,2}$ \\
\hline
\end{tabular}

степени, почти на все остальные показатели - в малой, а на перегрузку правых отделов - даже в незначительной. Данные, представленные в табл. 1, 2, полностью согласуются между собой.

В процессе морфогенеза НКМП (3-я и 4-я группы) наблюдается нивелирующее влияние последней на степень выраженности онтогенетических сдвигов ЭКГ (см. табл. 1). На патологическом фоне, создаваемом наличием НКМП, возрастные изменения ЭКГ-знаков практически не выражены и статистически значимы лишь для такого показателя, как удлинение интервала $Q T c$.

Значения d'C для большинства сравниваемых показателей ЭКГ в 3-й и 4-й группах (см. табл. 2) находятся в границах незначительной и малой величин; исключение составляет частота увеличения интервала $Q T c$ (в этом случае d'C соответствует средней степени).

Таким образом, сила влияния возрастного фактора на динамику показателей ЭКГ у больных, страдающих НКМП, крайне мала, а все выявленные изменения обусловлены развитием указанной ятрогенной патологии. Результаты сравнительного анализа изменений ЭКГ в парных 1-3-й и 2-4-й группах, т.е. у лиц одного возраста соответственно без НКМП и при ее наличии (см. табл. 1), еще раз подтверждают сказанное. Так, у молодых пациентов при развитии рассматриваемой кардиальной патологии существенно и статистически значимо ухудшаются почти все показатели ЭКГ, исключая аритмии. При этом сила влияния развития НКМП на изменения ЭКГ более заметна именно у молодых людей - d'C в паре 1-3-я группы у 3 показателей соот- ветствует малой степени, у 4 - средней и у 1 (диффузные мышечные изменения) - высокой (см. табл. 2).

У психически больных пожилого возраста, страдающих НКМП, также статистически значимо изменяется частота абсолютного большинства ЭКГ-знаков (см. табл. 1). Из 8 значений d'С в сравниваемых 2-й и 4-й группах (см. табл. 2) среднего уровня достигают 2 (причем один из показателей - все то же удлинение интервала $Q T c$ ); малая величина «размера эффекта» присуща 5 показателям и незначительная - лишь 1 (нарушения ритма).

Таким образом, анализ динамики изменений параметров ЭКГ в аспекте онтогенеза и при развитии НКМП показывает отсутствие существенного влияния возрастного фактора на частоту регистрации патологических ЭКГ-знаков у психически больных при наличии НКМП.

Обобщая все сказанное, можно констатировать, что при развитии НКМП у больных разного возраста решающее значение в генезе патологических изменений ЭКГ имеет не возрастной фактор, а побочное кардиотоксическое действие АП, приводящее в конечном счете к развитию НКМП.

Этот вывод крайне важен для клинической практики. Оказывается, что ведущий фактор в развитии такой витально опасной ятрогенной кардиальной патологии, как НКМП, - это прием АП. Отражением указанного процесса является динамика ЭКГ у пациентов; в то же время их возраст не играет существенной роли в генезе указанных изменений ЭКГ.

\begin{tabular}{|c|c|c|c|c|c|c|c|c|}
\hline $\begin{array}{l}\text { Сравниваемые } \\
\text { группы }\end{array}$ & $\begin{array}{l}\text { Нарушение } \\
\text { ритма }\end{array}$ & $\begin{array}{c}\text { Удлинение } \\
\text { интервала } \\
\text { QTс }\end{array}$ & $\begin{array}{c}\text { Нарушение } \\
\text { проводимости }\end{array}$ & $\begin{array}{l}\text { Диффуузные } \\
\text { мышечные } \\
\text { изменения }\end{array}$ & $\begin{array}{l}\text { Перегрузка } \\
\text { правых } \\
\text { отделов }\end{array}$ & $\begin{array}{c}\text { Гипертрофия } \\
\text { ЛЖ }\end{array}$ & $\begin{array}{c}\text { Снижение } \\
\text { электрической } \\
\text { активности миокарда }\end{array}$ & $\begin{array}{c}\text { Отклонение } \\
\text { ЭОС влево }\end{array}$ \\
\hline 1-2-я & $-0,41$ & 0,389 & 0,396 & 0,258 & 0,117 & 0,224 & 0,464 & 0,545 \\
\hline 3-4-я & $-0,054$ & 0,510 & 0,033 & 0,123 & 0,059 & 0,215 & 0,218 & 0,213 \\
\hline
\end{tabular}


Отсюда следует, что при АПТ у пациентов любого возраста требуется достаточно частое и регулярное проведение ЭКГ-исследований с целью максимально раннего выявления признаков развивающихся ятрогенных осложнений со стороны сердца и своевременной их коррекции.

\section{Литература}

1. Волков В.П. Естественные причины смерти больных шизофренией // Псих. здоровье. - 2013; 12: 52-7.

2. Волков В.П. К морфогенезу нейролептической кардиомиопатии: морфометрические и электрокардиографиические корреляции // Сиб. мед. журн. (Томск). - 2012; 27 (4): 29-33.

3. Волков В. Кардиотоксичность нейролептиков: клинические аспекты / Beau Bassin: LAP Lambert Academic Publ., 2018; 205.

4. Волков В.П. Клиническая характеристика нейролептической кардиомиопатии. Актуальные проблемы терапевтической клиники: коллективная научная монография. Под ред. В.П. Волкова / Новосибирск: СибАК, 2013; 94-116.

5. Волков В.П. Морфология миокарда в аспекте онтогенеза: морфометрическое исследование. Инновации в науке: сб. ст. по материалам L междунар. науч.-практ. конф. №10 (47) / Новосибирск: СибАК, 2015; 93-100.

6. Волков В.П. Фенотиазиновая дилатационная кардиомиопатия: некоторые аспекты клиники и морфологии // Клин. мед. - 2009; 8: 13-6.

7. Орлов В.Н. Руководство по электрокардиографии. 7-е изд. / М.: МИА, 2012; 560 .

8. Прокопьева С.Н., Мовчан Л.А., Исхакова Г.Г. и др. Особенности электрокардиографической диагностики у лиц старших возрастных групп // Практ. мед. - 2008; 4 (28): 21-9.

9. Cohen J., Cohen P., West S. et al. Applied multiple correlation/regression analysis for the behavioral sciences. $3^{\text {rd }}$ ed. / Mahwah, NJ: Lawrence Erlbaum Ass., 2003; 736. DOI: $10.4324 / 9780203774441$

10. Buckley N., Sanders P. Cardiovascular adverse effects of antipsychotic drugs // Drug Saf. - 2000; 23 (3): 215-28. DOI: 10.2165/00002018-20002303000004

11. Cohen J. Statistical power analysis for the behavioral sciences. 2nd ed. / Hillsdale, NJ: Lawrence Erlbaum Ass., 1988; 567.

12. Jones J., Srodulski Z., Romisher S. The aging electrocardiogram // Am. J. Emerg. Med. - 1990; 8 (3): 240-51. DOI: 10.1016/0735-6757(90)90331-S

13. Khane R., Surdi A., Bhatkar R. Changes in ECG pattern with advancing age // J. Basic Clin. Physiol. Pharmacol. - 2011; 22 (4): 97-101. DOl: 10.1515/ JBCPP.2011.017

14. Mackin P. Cardiac side effects of psychiatric drugs // Hum. Psychopharmacol. - 2008; 23 (Suppl. 1): 3-14. DOI: 10.1002/hup.915

15. Thomas S. Drug-induced QT interval prolongation // Br. J. Clin. Pharmacol. - 1996; 42 (3): 399-400.

\section{THE AGE OF PATIENTS AND THE DYNAMICS OF ECG IN NEUROLEPTIC CARDIOMYOPATHY}

V. Volkov, Candidate of Medical Sciences

Tver Center of Forensic Examinations

The side cardiotoxic effect of antipsychotics, which leads to cardiac disease, rather than an age factor, has been established to have a decisive impact on electrocardiographic changes in the development of neuroleptic cardiomyopathy. Key words: cardiology, psychiatry, antipsychotic drugs, cardiotoxicity, neuroleptic cardiomyopathy, electrocardiogram changes, impact of age.

For citation: Volkov V. The age of patients and the dynamics of ECG in neuroleptic cardiomyopathy // Vrach. - 2018; 29 (9): 65-67. https://doi. org/10.29296/25877305-2018-09-15 